\title{
Prediction of Multipreform Shapes in Warm Forming with Experimental Verification
}

\author{
T. F. KONG ${ }^{1,2}$ and L. C. $\mathrm{CHAN}^{1,3}$ \\ 1.-Department of Industrial and Systems Engineering, The Hong Kong Polytechnic University, \\ Hung Hom, Kowloon, Hong Kong, People's Republic of China. 2.-e-mail: tf.kong@polyu.edu.hk. \\ 3.—e-mail: lc.chan@polyu.edu.hk
}

This study uses a computer-aided simulation approach to predict the multipreform shapes of warm-forming intricate components. Nearly $100 \%$ of the scraps of primary hollow preforms are used to make secondary hollow preforms. This study simultaneously fabricates the AISI 316L stainless steel watch bezel by using scraps from the corresponding watch case. The appropriate preforms are designed with the aid of computer simulation such that die filling is completed, flash is reduced, and forming load is decreased. The specimens were prepared by custom-made tooling to verify the simulation results. Furthermore, the forming facilities are specially configured to carry out the physical experiments. Engineers eventually gain a better understanding of the warm-forming process using computer simulation. Moreover, they are able to design accurate preforms and fully utilize the material, which leads to a 50\% improvement of the material utilization rate. The full material utilization also saves $40 \%$ and $20 \%$ of the total production cost and time, respectively.

\section{INTRODUCTION}

Most metal-formed components are hollow objects (e.g., watch cases, watch bezels, and spur gears). Forming hollow components using solid blanks or preforms in one single operation involves a high degree of deformation. This deformation results in increased forming loads and shortened die life, which make this process unwise and impractical. Reasonably, the hollow preform should be employed to form the hollow component. The forming load is reduced if the hollow preform is correctly designed. Moreover, its scrap from the center hole is reused to produce other components.

A generic procedure has been developed for integrating computer-aided design $(\mathrm{CAD})$ and computer-aided engineering into the bulk-forming design. ${ }^{1-10}$ Engineers effectively minimize the number of trial runs using these tools and software. As a result, cost, time, and resources are significantly reduced. Most of the previous studies have investigated forming objects or problems typically related to rib-web parts including H-shaped parts, ${ }^{11-17}$ connecting rods, ${ }^{17-19}$ and disks. ${ }^{20-22}$
Moreover, generalizing blank or preform design for various bulk-forming types follows very few rules and guidelines. Only the empirical rules of Lange and Meyer-Nolkemper ${ }^{23}$ cover most of the axisymmetric and nonaxisymmetric formed components. Accordingly, Lange and Meyer-Nolkemper ${ }^{23}$ suggested designing the blank or preform with an outer profile nearly the same as the largest slice at the cross-section of the formed component. However, the literature mainly focuses on forming solid components and preforms without a center hole (i.e., nonhollow objects). The preforms in these cases should be designed in solid objects. Hence, no scrap is used as material for forming another preform.

One blank metal is able to produce at least a pair of hollow components. The scraps are reused to produce subsequent component if the scrap volume produced during the primary component formation is larger than that of the secondary component. The simple concept is shown in Fig. 1 as a flowchart highlighting how the secondary hollow preform is subsequently produced. However, concept implementation is very difficult because the preforms have a large range of possible configurations that 
depend on the desired shapes of the final formed components.

Apart from the preform design, material temperature is another factor highly influencing the effectiveness of bulk forming. The formability of most metals under room temperature is relatively lower than that under elevated temperatures. A large number of dies and multistage operations are involved in the manufacture of metallic components using cold forming. The process is improved by employing warm forming with an operation carried out above room temperature and below the workpiece recrystallization temperature. The main advantage of this method is that it practically attains a close tolerance similar to cold forming and achieves nearly the same formability with that of hot forming. ${ }^{24,25}$ Under suitable conditions, warm forming effectively forms preheated metals into desired shapes in one single stroke. The cost of heating a workpiece up to its hot-forming temperatures is very expensive. The cost of the overall manufacturing process is reduced if the operation temperature is decreased. ${ }^{26}$

This article provides a solution based on the computer simulation methodology to demonstrate a cost-saving and effective approach. The methodology aids the design of both primary and secondary hollow preforms for warm forming intricate components. The primary objective of this study is to determine the multipreform shapes to ensure that the metal can completely fill up the die cavity with minimum material loss into flash. An analytical approach using $\mathrm{CAD}$ and numerical simulation is proposed to predict the multipreform shapes accurately. This study uses the AISI 316L stainless steel watch bezel produced from the scrap of the corresponding watch case. Moreover, a finite-element (FE) simulation software (i.e., DEFORM-3D; Scientific Forming Technologies Corporation, Columbus, $\mathrm{OH}$ ) is used to predict the die filling of the warm-forming processes to achieve a significant and efficient improvement of the material utilization rate (i.e., over $50 \%$ ). The scrap taken from the center hole of a primary hollow preform used to form the watch case is reused to produce the secondary hollow preform for watch bezel. Custom-made warm-forming dies and a mechanical press are employed to produce the specimens. These specimens are used to verify and compare the results of the simulations and experiments. The proposed methodology allows engineers to use the material fully by gaining a better understanding of the warm-forming process.

\section{METHODOLOGY}

\section{Configurations and Material of Formed Com- ponents}

This study used a circular nonaxisymmetric watch case as the primary formed component. The secondary formed component was an axisymmetric watch bezel. The NX (Siemens PLM Software, Plano, TX) CAD software was employed to construct 3D models. Model shapes and dimensions are presented in Fig. 2. The watch case was a good example for warm forming because of its intricate shape and compact size. The volume of the primary (i.e., $V_{\text {cI }}$ ) and secondary formed components (i.e., $V_{\text {cII }}$ ) were $3,753.86 \mathrm{~mm}^{3}$ and $2,749.69 \mathrm{~mm}^{3}$, respectively. For these types of compact-size components, a hollow preform was initially produced from a thick sheet metal, followed by warm forming using closed-die in one single stroke. The parting lines of the warmforming dies were placed at the areas with largest cross-sections, center holes, and around the entire perimeters. Flashes with different thicknesses were extruded at parting lines after the die cavities were completely filled up. Other traditional processes (e.g., trimming of flashes and machining) were then applied to finish the components construction.

The formed material was an austenitic stainless steel (i.e., AISI 316L) with excellent strength and corrosion resistance. The flow stress $\bar{\sigma}$ data used in the FE simulations were obtained from a handbook published by the ASM International. ${ }^{27}$ The data covered strain $\bar{\varepsilon}=0.1,0.2,0.3,0.4$, and 0.5 ; temperature $T=600^{\circ} \mathrm{C}, 700^{\circ} \mathrm{C}, 800^{\circ} \mathrm{C}, 900^{\circ} \mathrm{C}$, and $1000^{\circ} \mathrm{C}$; and strain rate $\dot{\bar{\varepsilon}}=0.001,0.01,0.1,1,10$, and 100/s. The approximate flow stress $\bar{\sigma}$ and strain $\bar{\varepsilon}$ relationship was induced by an exponential equation Eq. 1 for conditions that exceeded the bounds of the preceding $\bar{\varepsilon}, T$, or $\dot{\bar{\varepsilon}}$ values: ${ }^{27}$

$$
\bar{\sigma}=K(\bar{\varepsilon})^{n}
$$

where $K$ is the strain coefficient and $n$ is the strainhardening exponent obtained based on further DEFORM-3D computation (Table I).

\section{Experimental Setup for Warm Forming}

The warm-forming dies were mounted inside a mechanical press with a maximum load capacity of 300 tons. The preforms were heated up to its warmforming temperature using a high radio-frequency (RF) induction heater. The setup of the warmforming equipment is illustrated in Fig. 3. The warm-forming dies were made according to the final shapes of the formed component because this process was a single-stroke forming operation. The operation included top and bottom dies, punch, and ejector. The configuration was designed for a backward-extrusion process, where the metal flows in the opposite direction of the punch during the forming process. A heat-treated hot work tool steel W302 equivalent to AISI H13 had good temper resistance and superior strength under warmforming conditions. Hence, it was used as the tooling material. An allowance of $0.8 \%$ was added to each die impression to compensate for the thermal expansion of $1.926 \times 10^{-6 /} \mathrm{C}$ at around $870^{\circ} \mathrm{C}^{28}$ during the warm-forming process and the shrinkage 


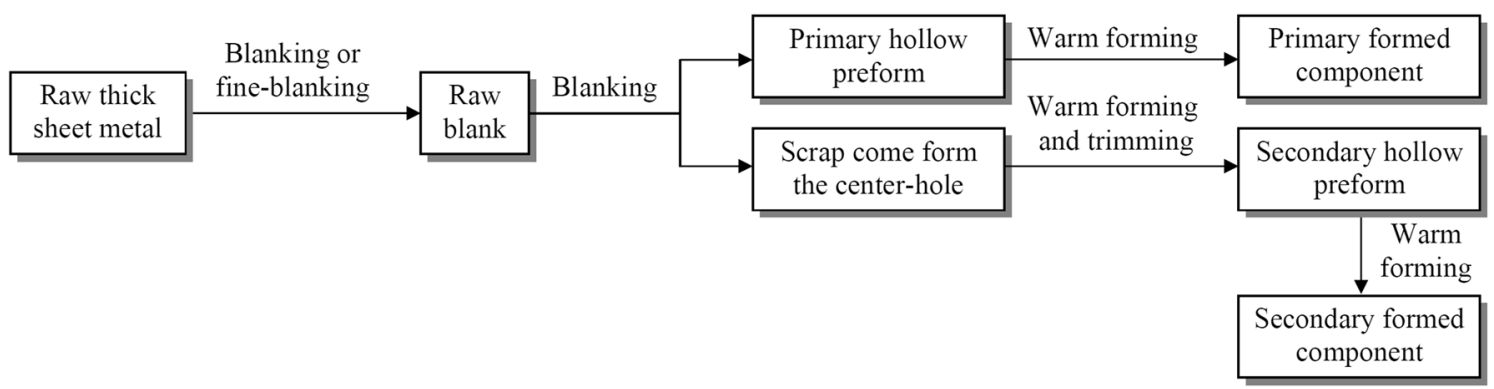

Fig. 1. The concept of using the scrap taken from the center hole of the primary hollow preform to make subsequent hollow preform for warm forming the secondary formed component.

Example of the primary

formed component - watch case

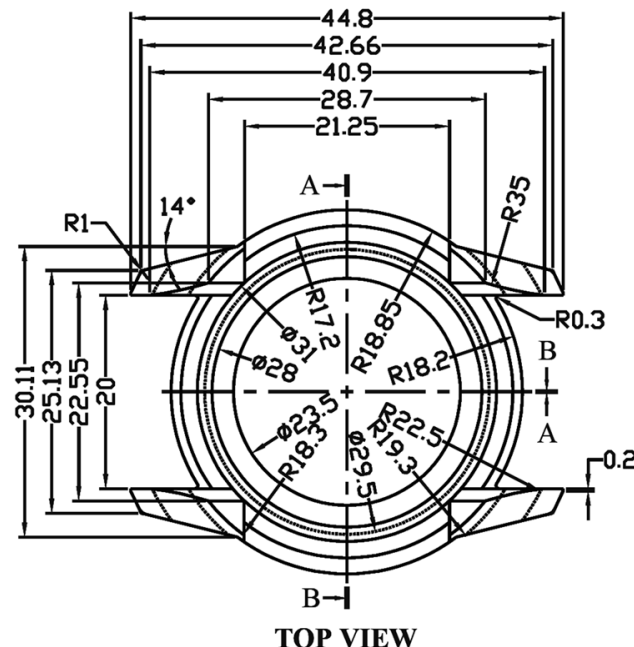

TOP VIEW

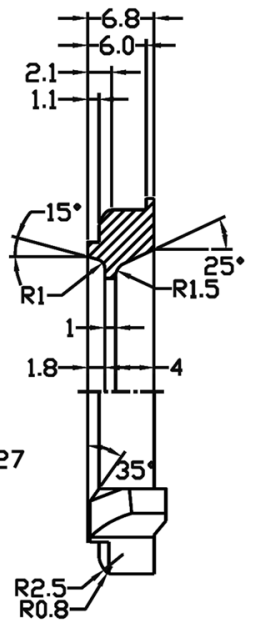

A-A

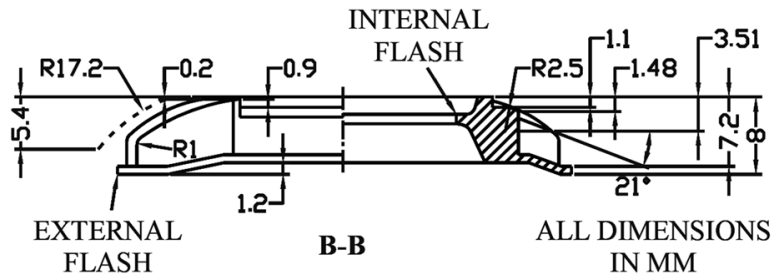

Example of the primary formed component - watch bezel

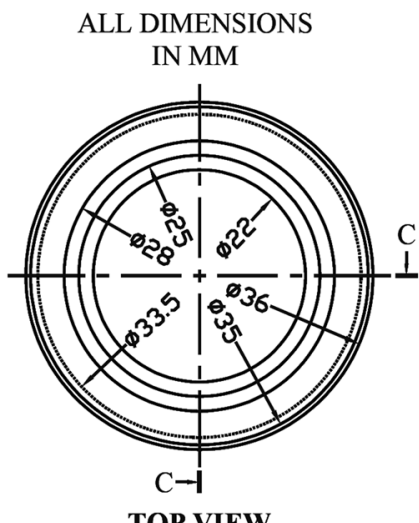

TOP VIEW

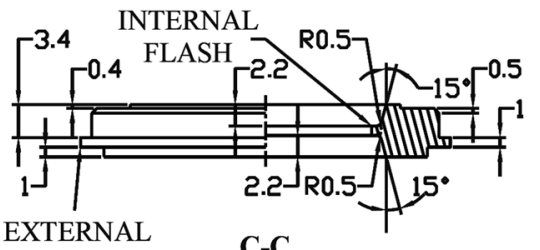

FLASH

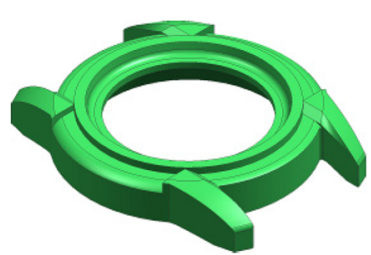

Primary formed component

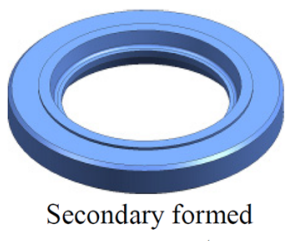

component

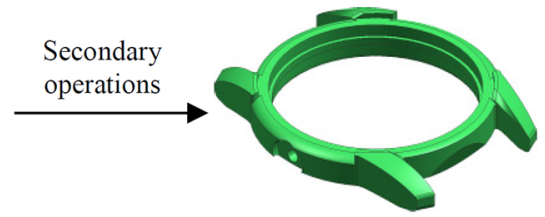

Primary finished component (after machining)

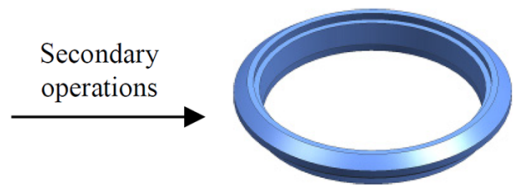

Secondary finished component (after machining)

Fig. 2. The overall configurations of the formed components. 
Table I. The $K$ and $n$ values for AISI 316L stainless steel at the working ranges of temperatures and strain rates used in this study

\begin{tabular}{|c|c|c|c|c|c|c|c|c|c|c|}
\hline \multirow{3}{*}{$\begin{array}{l}\text { Strain } \\
\text { rate, } \dot{\bar{\varepsilon}}(/ \mathbf{s})\end{array}$} & \multicolumn{10}{|c|}{ Temperature $(T)$} \\
\hline & \multicolumn{2}{|c|}{$600^{\circ} \mathrm{C}$} & \multicolumn{2}{|c|}{$700^{\circ} \mathrm{C}$} & \multicolumn{2}{|c|}{$800^{\circ} \mathrm{C}$} & \multicolumn{2}{|c|}{$900^{\circ} \mathrm{C}$} & \multicolumn{2}{|c|}{$1000^{\circ} \mathrm{C}$} \\
\hline & $\boldsymbol{K}$ & $n$ & $\boldsymbol{K}$ & $n$ & $\boldsymbol{K}$ & $n$ & $\boldsymbol{K}$ & $n$ & $\boldsymbol{K}$ & $n$ \\
\hline 0.001 & $\overline{704.3}$ & $\overline{0.23}$ & $\overline{454.4}$ & $\overline{0.14}$ & $\overline{262.3}$ & $\overline{0.07}$ & $\overline{164.0}$ & $\overline{0.07}$ & $\overline{109.6}$ & $\overline{0.10}$ \\
\hline 0.01 & 764.3 & 0.24 & 619.2 & 0.18 & 415.9 & 0.18 & 221.1 & 0.05 & 147.3 & 0.04 \\
\hline 0.1 & 786.6 & 0.26 & 643.2 & 0.23 & 450.9 & 0.12 & 300.6 & 0.10 & 187.9 & 0.05 \\
\hline 1 & 731.2 & 0.21 & 610.4 & 0.18 & 508.9 & 0.15 & 358.4 & 0.07 & 246.4 & 0.05 \\
\hline 10 & 706.4 & 0.24 & 610.7 & 0.20 & 503.2 & 0.16 & 435.5 & 0.13 & 360.0 & 0.11 \\
\hline 100 & 783.7 & 0.23 & 606.8 & 0.19 & 547.5 & 0.20 & 469.7 & 0.15 & 375.0 & 0.10 \\
\hline
\end{tabular}

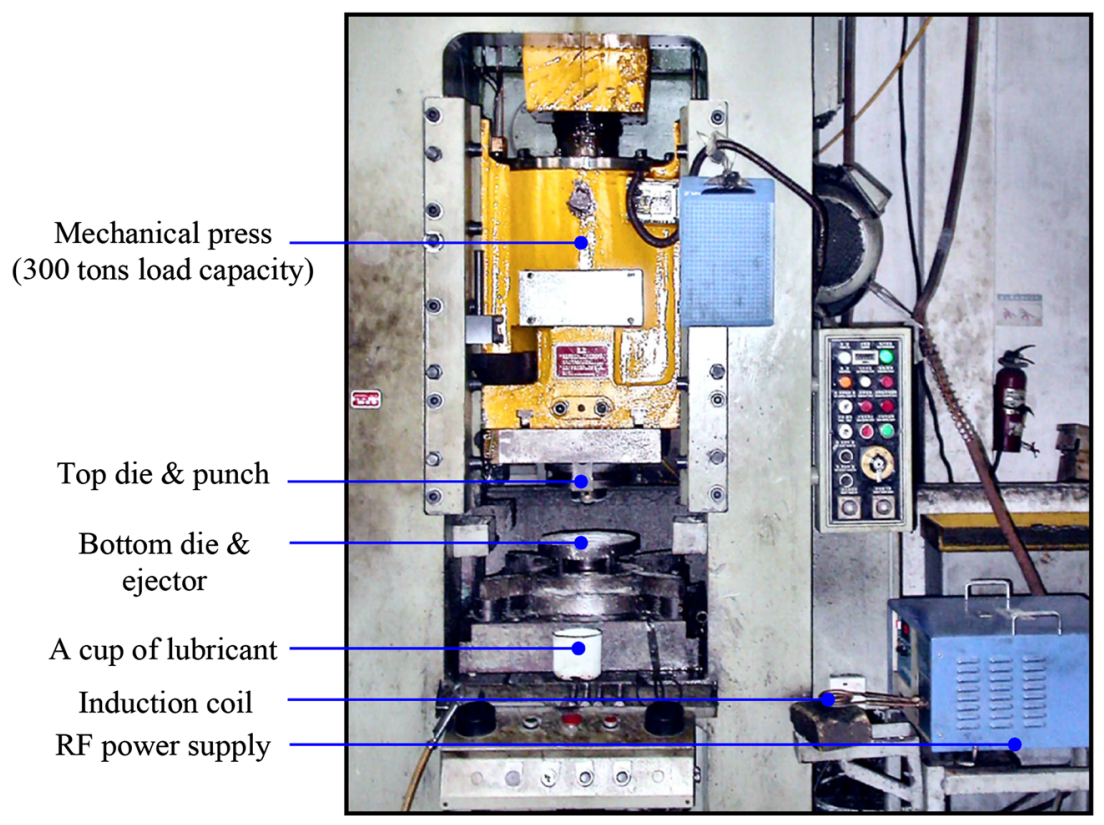

Fig. 3. The setup of warm-forming equipment.

after workpiece cooling. A lubricant W-400 with an approximate 0.25 coefficient of friction was spread over the tooling surfaces.

\section{Hollow Preform Design}

Lange and Meyer-Nolkemper ${ }^{23}$ established three rules: (I) the cross-sectional area for each preform slice along the height axis should be equal to that of the formed component augmented by the area necessary for flash, (II) all the concave radii of the preform should be larger than the radii of the formed component, and (III) the dimensions in the forming direction of the preform should be larger than that of the formed component so that metal flow is mostly of upsetting rather than extrusion type. In this manner, the material was laterally squeezed toward the die cavity with little shear at the tool-workpiece interface. This condition minimized the friction and the forming load, thereby reducing the wear along the die surface.
The preceding rules also guide the design of the hollow preform outer profile. We provided an the outer profile, which was $0.2 \mathrm{~mm}$ smaller than the outer profile of the formed component, to ensure that the preform was properly located inside the bottom die (Fig. 4). The hollow preforms were assumed to be fabricated from raw, thick sheet metals using either the blanking or the fine-blanking process. The blanked preform had a uniform crosssection along the height axis. Hence, the geometric variables affecting the metal flow during the forming process were the center-hole diameters $d_{\mathrm{I}}$ and $d_{\mathrm{II}}$ for the primary and secondary hollow preforms, respectively, and the material thickness $t_{\mathrm{I}}$ and $t_{\mathrm{II}}$ for the primary and secondary hollow preforms, respectively.

\section{Determination of Center Hole Diameters}

The preform geometries were modeled by NX. The punch and ejector designs were highly dependent on 
Schematic diagram of primary hollow preform

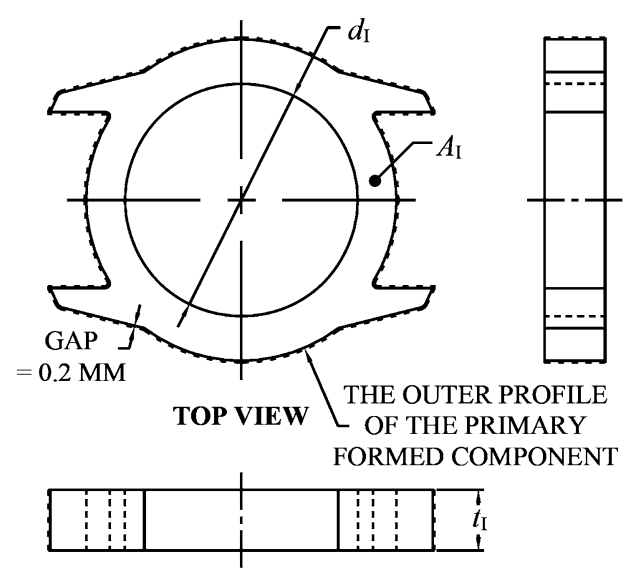

FRONT VIEW

(a)
Schematic diagram of secondary hollow preform
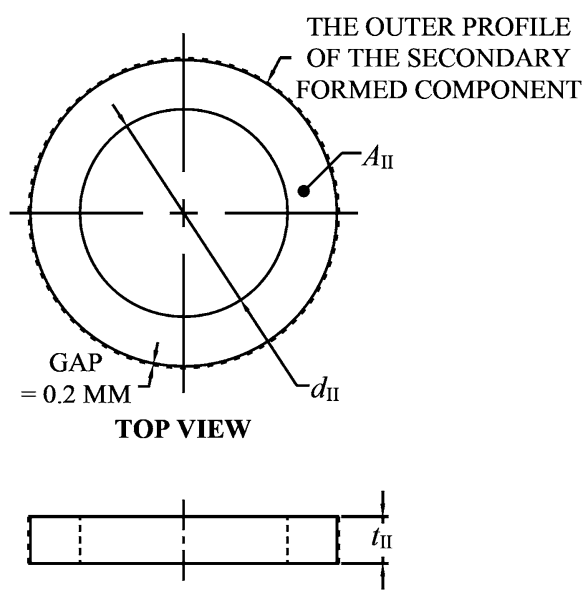

FRONT VIEW

(b)

Fig. 4. The configurations of (a) the primary hollow preform and (b) the secondary hollow preform.

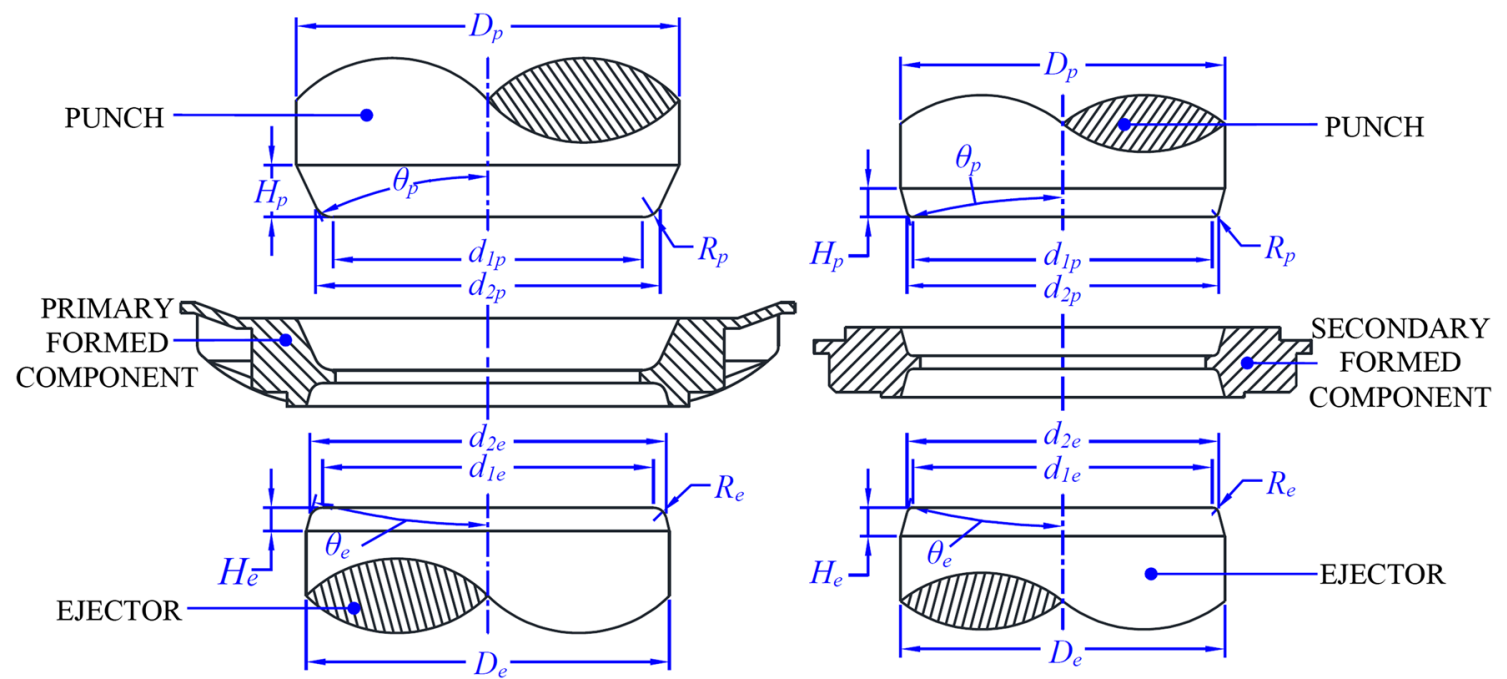

Fig. 5. The geometric variables of the protrusions of the punches and ejectors for warm forming the hollow components.

$d_{\mathrm{I}}$ and $d_{\mathrm{II}}$. The punch and ejector configurations of the primary and secondary formed components for simulation are illustrated in Fig. 5. The punch and ejector geometries followed the inner contours of the formed components. The protrusions were tapered, and the corners were rounded and smooth with the appropriate radii.

The end-face diameters of the punches and the ejectors included the larger end-face punch diameter $d_{1 \mathrm{p}}$, smaller end-face punch diameter $d_{2 \mathrm{p}}$, larger end-face ejector diameter $d_{1 \mathrm{e}}$, and smaller end-face ejector diameter $d_{2 \mathrm{e}}$. The $d_{1 \mathrm{p}}, d_{2 \mathrm{p}}, d_{1 \mathrm{e}}$, and $d_{2 \mathrm{e}}$ values were determined using Eqs. 2-5:

$$
d_{1 \mathrm{p}}=D_{\mathrm{p}}-2 H_{p} \tan \theta_{\mathrm{p}}-2 R_{\mathrm{p}} \tan \left(\frac{\pi}{4}-\frac{\theta_{\mathrm{p}}}{2}\right)
$$

$$
\begin{gathered}
d_{1 \mathrm{e}}=D_{\mathrm{e}}-2 H_{\mathrm{e}} \tan \theta_{\mathrm{e}}-2 R_{\mathrm{e}} \tan \left(\frac{\pi}{4}-\frac{\theta_{\mathrm{e}}}{2}\right) \\
d_{2 \mathrm{p}}=2 R_{\mathrm{p}} \tan \left(\frac{\pi}{4}-\frac{\theta_{\mathrm{p}}}{2}\right) \sin \theta_{\mathrm{p}}+D_{\mathrm{p}}-2 H_{\mathrm{p}} \tan \theta_{\mathrm{p}} \\
d_{2 \mathrm{e}}=2 R_{\mathrm{e}} \tan \left(\frac{\pi}{4}-\frac{\theta_{\mathrm{e}}}{2}\right) \sin \theta_{\mathrm{e}}+D_{\mathrm{e}}-2 H_{\mathrm{e}} \tan \theta_{\mathrm{e}}
\end{gathered}
$$

where $D_{\mathrm{p}}$ and $D_{\mathrm{e}}$ are the punch and ejector diameters, respectively; $H_{\mathrm{p}}$ and $H_{\mathrm{e}}$ are the punch and 
Table II. The geometric values for the primary hollow preforms

\begin{tabular}{|c|c|c|c|c|c|c|c|c|c|}
\hline $\begin{array}{l}\text { Primary } \\
\text { hollow } \\
\text { preform }\end{array}$ & $\underset{\left(\mathbf{m m}^{3}\right)}{V_{\mathbf{c I}}}$ & $\underset{\left(\mathbf{m m}^{\mathbf{3}}\right)}{V_{\mathbf{f I}}}$ & $\underset{\left(\mathbf{m m}^{\mathbf{3}}\right)}{V_{\mathbf{I}}}$ & $\underset{(\mathbf{m m})}{d_{\mathbf{I}}}$ & $\underset{\left(\mathbf{m m}^{2}\right)}{A_{\mathbf{I}^{2}}}$ & $\begin{array}{c}\boldsymbol{t}_{\mathbf{I}} \\
(\mathbf{m m})\end{array}$ & $\begin{array}{c}\text { Actual } \\
\text { thickness, } \\
t(\mathbf{m m})\end{array}$ & $\begin{array}{c}\text { Actual } \\
\text { volume }\left(\mathbf{m m}^{\mathbf{3}}\right)\end{array}$ & $\begin{array}{c}\text { Actual \% } \\
\text { by flash } \\
\text { volume }\end{array}$ \\
\hline $\mathrm{P} 1$ & $3,753.9$ & 375.4 & $4,129.3$ & $23.8\left(=d_{1 p}\right)$ & 715.9 & 5.8 & 6.0 & $4,295.4$ & $14.4 \%$ \\
\hline $\mathrm{P} 2$ & $3,753.9$ & 375.4 & $4,129.3$ & $26.6\left(=d_{2 p}\right)$ & 605.0 & 6.8 & 7.0 & $4,235.0$ & $12.8 \%$ \\
\hline P3 & $3,753.9$ & 375.4 & $4,129.3$ & $25.5\left(=d_{1 \mathrm{e}}\right)$ & 650.1 & 6.4 & 6.5 & $4,225.7$ & $12.6 \%$ \\
\hline $\mathrm{P} 4$ & $3,753.9$ & 375.4 & $4,129.3$ & $27.5\left(=d_{2 \mathrm{e}}\right)$ & 566.8 & 7.3 & 7.5 & $4,251.0$ & $13.2 \%$ \\
\hline P5 & $4,187.6$ & 209.4 & $4,397.0$ & 0 & $1,160.8$ & 3.8 & 4.0 & $4,643.2$ & $10.9 \%$ \\
\hline
\end{tabular}

Table III. The geometric values for the secondary hollow preforms

\begin{tabular}{|c|c|c|c|c|c|c|}
\hline $\begin{array}{l}\text { Secondary } \\
\text { hollow preform } \\
\end{array}$ & $V_{\text {cII }}\left(\mathrm{mm}^{3}\right)$ & $V_{\text {fII }}\left(\mathbf{m m}^{\mathbf{3}}\right)$ & $V_{\text {II }}\left(\mathrm{mm}^{\mathbf{3}}\right)$ & $d_{\mathrm{II}}(\mathbf{m m})$ & $A_{\text {II }}\left(\mathbf{m m}^{2}\right)$ & $t_{\mathrm{II}}(\mathrm{mm})$ \\
\hline PA & $2,749.7$ & 137.5 & $2,887.2$ & $\left.23.0,=d_{1 \mathrm{p}}\right)$ & 579.9 & 5.0 \\
\hline $\mathrm{PB}$ & $2,749.7$ & 137.5 & $2,887.2$ & $\left.24.1,=d_{2 p}\right)$ & 539.2 & 5.4 \\
\hline
\end{tabular}

ejector protrusion heights, respectively; $\theta_{\mathrm{p}}$ and $\theta_{\mathrm{e}}$ are the punch and ejector draft angles; and $R_{\mathrm{p}}$ and $R_{\mathrm{e}}$ are the punch and ejector corner radii.

This study used the simulation software to test five different primary hollow preform designs (i.e., $\mathrm{P} 1, \mathrm{P} 2, \mathrm{P} 3, \mathrm{P} 4$, and $\mathrm{P} 5) . d_{\mathrm{I}}$ of the $\mathrm{P} 1, \mathrm{P} 2, \mathrm{P} 3$, and $\mathrm{P} 4$ preforms were equal to $d_{1 \mathrm{p}}, d_{2 \mathrm{p}}, d_{1 \mathrm{e}}$, and $d_{2 \mathrm{e}}$ of their tooling. P5 was a nonhollow, solid metal block used to compare the required forming loads between the hollow and nonhollow preforms.

The punch and ejector geometries for forming the secondary formed component were determined in the same manner with that of the primary formed component. The simulation software tested two different designs (i.e., PA and PB). $d_{\mathrm{II}}$ of the two designs were then set to $d_{1 \mathrm{p}}$ and $d_{2 \mathrm{p}}$ of their tooling.

\section{Determination of Material Thicknesses}

The CAD software was then employed to determine the cross-sectional areas $A_{\mathrm{I}}$ and $A_{\mathrm{II}}$ for the primary and secondary hollow preforms. Assuming the volume of the preform equals the volume of the formed component plus flash, $t_{\mathrm{I}}$ and $t_{\mathrm{II}}$ were calculated by Eqs. 6 and 7:

$$
\begin{gathered}
t_{\mathrm{I}}=\frac{V_{\mathrm{cI}}+V_{\mathrm{fI}}}{A_{\mathrm{I}}} \\
t_{\mathrm{II}}=\frac{V_{\mathrm{cII}}+V_{\mathrm{fII}}}{A_{\mathrm{II}}}
\end{gathered}
$$

where $V_{\mathrm{cI}}$ and $V_{\mathrm{cII}}$ are the volumes of the primary and secondary hollow preforms, respectively; and $V_{\mathrm{fI}}$ and $V_{\mathrm{fII}}$ are the flash volumes of the primary and secondary formed components, respectively.

\section{Flash Volumes}

Minimizing the amount of metal loss into flash was one of the most significant preform design requirements. Accordingly, Biswas et al. ${ }^{13}$ successfully reduced the excess material (i.e., flash) to $6 \%$ and $8.75 \%$ of their formed components using CAD. The excess material of the secondary formed component (i.e., watch bezel) in this study was relatively small and $V_{\text {fII }}$ was $5 \%$ of $V_{\text {cII }}$. The primary formed component was a nonaxisymmetric object with many intricate features. Hence, forming was more difficult than that of the secondary formed component and the rib-web components demonstrated in the previous study. ${ }^{13}$ Correspondingly, $V_{\text {fI }}$ for P1, P2, P3, and P4 was theoretically set to $10 \%$ of $V_{\mathrm{cI}}$. P5 did not produce internal flash. Hence, $V_{\text {fI }}$ for P5 was set to $5 \%$ of $V_{\text {cI }}$.

The primary hollow preform was blanked from the raw thick metal/plate supplied with thicknesses in steps of $0.5 \mathrm{~mm}$ (e.g., $6.0 \mathrm{~mm}, 6.5 \mathrm{~mm}, 7.0 \mathrm{~mm}$, and $7.5 \mathrm{~mm}$ ). Therefore, $t_{\mathrm{I}}$ calculated by Eq. 6 was rounded up to the actual thickness $t$ of the sheet/ plate. The values of all the geometric variables for the primary and secondary hollow preforms are listed in Tables II and III. The flash was around $10.9 \%$ to $14.4 \%$ of $V_{\mathrm{cI}}$, which was better than the average value of $25 \%$ as in the case of conventional design. ${ }^{13}$

\section{Applicable Preform Design Solution}

An appropriate primary hollow preform design should fulfill two criteria: (I) It should produce defect-free formed component with minimum flash and (II) the scrap should have sufficient volume to produce the secondary formed component. 
Table IV. The dimensions, cross-sectional areas, and volumes of the scraps of the primary hollow preforms

\begin{tabular}{|c|c|c|c|c|c|}
\hline Scrap & $d_{\mathrm{I}}(\mathbf{m m})$ & $d_{\mathbf{s}}(\mathbf{m m})$ & $t(\mathbf{m m})$ & $A_{\mathrm{s}}\left(\mathrm{mm}^{2}\right)$ & $V_{\mathrm{s}}\left(\mathrm{mm}^{3}\right)$ \\
\hline Scrap of P1 & 23.8 & 23.20 & 6.0 & 422.7 & $2,536.4$ \\
\hline Scrap of P2 & 26.6 & 25.90 & 7.0 & 526.9 & $3,688.0$ \\
\hline Scrap of P3 & 25.5 & 24.85 & 6.5 & 485.0 & $3,152.5$ \\
\hline Scrap of P4 & 27.5 & 26.75 & 7.5 & 562.0 & $4,215.0$ \\
\hline
\end{tabular}

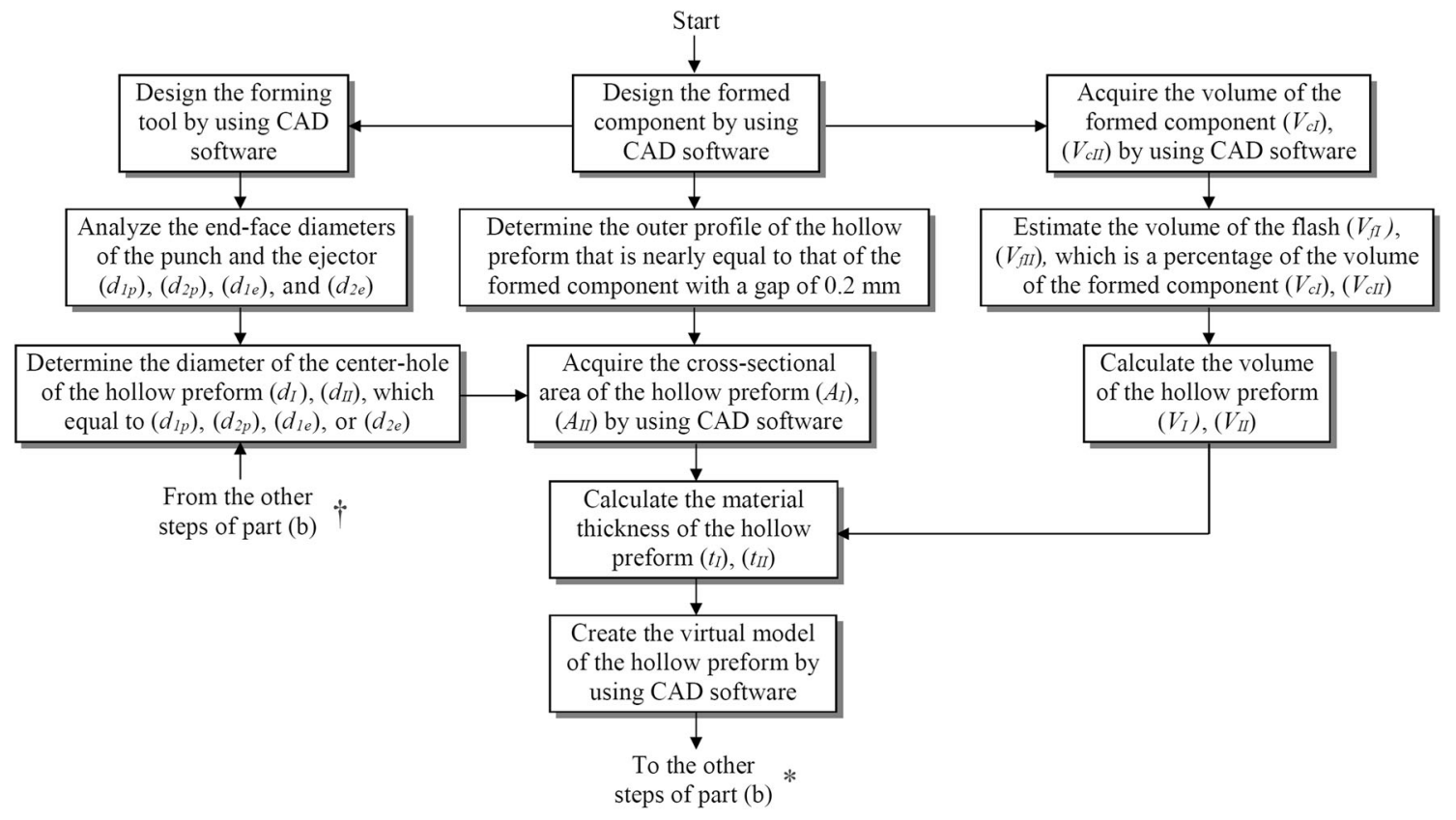

(a)

Fig. 6. The approach to designing the primary and secondary hollow preforms.

The secondary formed component was not produced in one single operation because its shape significantly differed from the scrap. An intermediate preform was produced from the scrap instead. The volume and geometry of intermediate preform were determined after the $d_{\mathrm{II}}$ and $t_{\mathrm{II}}$ values were found. The scrap volume $V_{\mathrm{s}}$ had to be larger than the volume of the intermediate preform plus flash. Consequently, $V_{\mathrm{s}}$ of $\mathrm{P} 1, \mathrm{P} 2, \mathrm{P} 3$, and $\mathrm{P} 4$ were determined in this manner.

The primary hollow preform was produced either by the blanking or the fine blanking process. The scrap diameter $d_{\mathrm{s}}$ was different from $d_{\mathrm{I}}$ because of the gap between the punch and the die. $d_{\mathrm{s}}$ was be determined using Eq. 8:

$$
d_{s}=d_{I}-2 c_{t} t
$$

where $c_{\mathrm{t}}$ is the clearance percentage equal to $5 \%$ and $0.5 \%$ for blanking and fine-blanking processes, respectively. ${ }^{29}$ The scraps of $\mathrm{P} 1, \mathrm{P} 2, \mathrm{P} 3$, and $\mathrm{P} 4$ were cylindrical billets. Hence, their cross-sectional areas $A_{\mathrm{s}}$ and volumes $V_{\mathrm{s}}$ were simply calculated. The calculation results are tabulated in Table IV.
The applicable solution with minimum $t$ was usually considered as the most suitable among the multiple design solutions satisfying the core-forming requirements (i.e., complete die filling and defect-free forming) because the thinner sheet metal reduced material cost. The forming load also occasionally played an important role because it reduced the die wear. The whole design procedure is summarized in Fig. 6.

\section{Process Modeling}

The FE simulation software (i.e., DEFORM-3D) was used to simulate the warm-forming processes under the conditions listed in Table V. All the geometric models used in this study were quartered to improve the accuracy for metal-flow prediction, speed up computations, and increase the number of meshes for each volume. All the tool components were assumed as rigid-body objects. The preforms were modeled using rigid viscoplastic formulation, which only considered plastic deformation because elastic deformation was not significant in this bulk forming problem. Furthermore, elastic deformation 


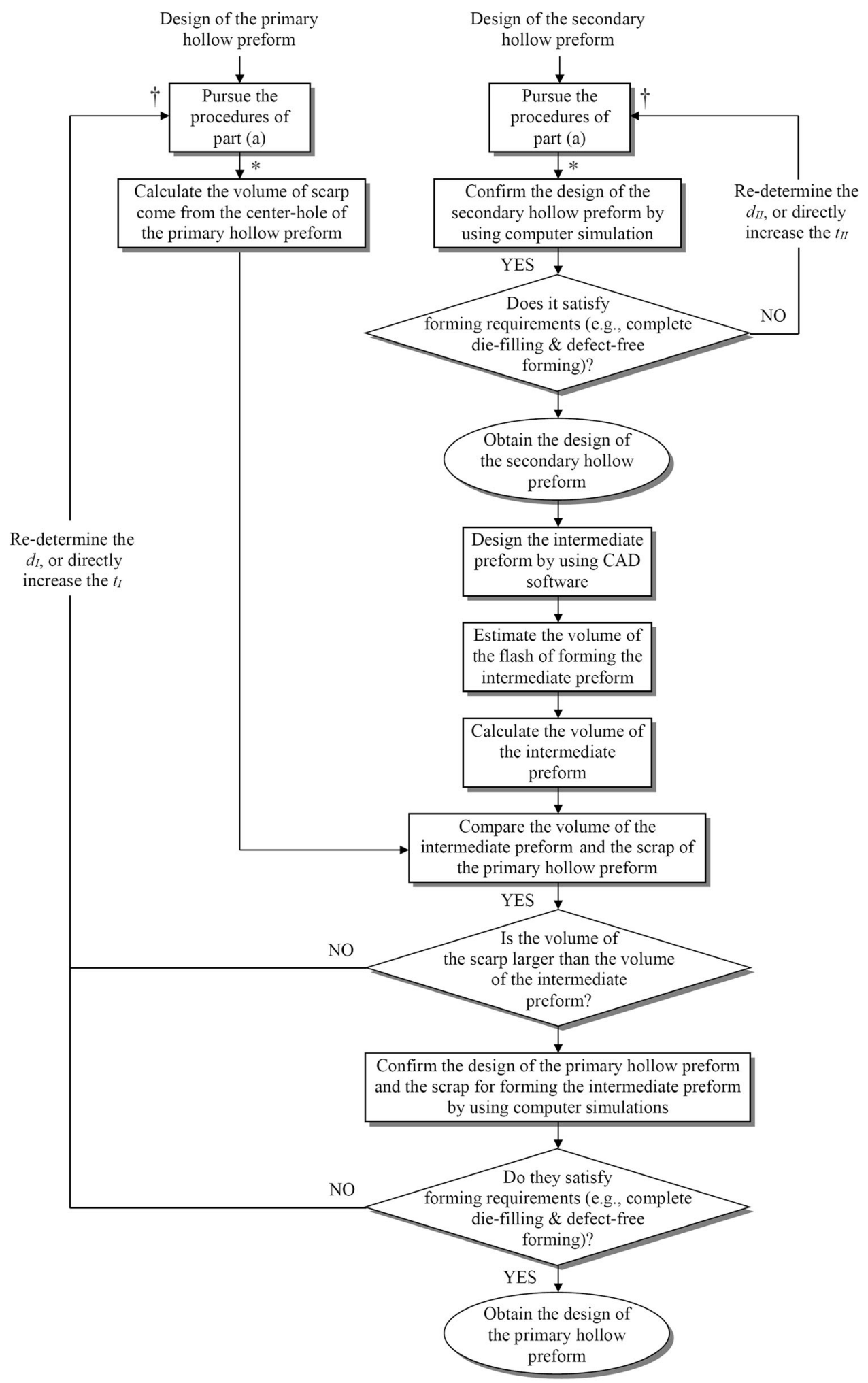

(b)

Fig. 6. continued.

was neglected to simplify and accelerate convergence in the iteration. The metal deformation behaviors were modeled using the flow stress data of the AISI 316L stainless steel published in the metal handbook. ${ }^{27}$ The thermal properties including thermal conductivity and heat capacity were taken 
from the literature edited by the Airco Company International. ${ }^{28}$ An emissivity of 0.5 was taken to represent the surface quality of the raw thick sheet

Table V. Process conditions for the warm-forming simulations

\begin{tabular}{lcc}
\hline Simulation parameter & & Value/setting \\
\cline { 1 - 1 } $\begin{array}{l}\text { Iteration method } \\
\text { Deformation solver and } \\
\text { temperature solver }\end{array}$ & & $\begin{array}{c}\text { Newton-Raphson } \\
\text { Sparse }\end{array}$ \\
Workpiece-tool shear friction factor & & 0.25 \\
Coefficient of heat transfer & $11 \mathrm{~W} / \mathrm{m}^{2} \mathrm{~K}$ \\
Ram speed of top die and punch & & $40 \mathrm{~mm} / \mathrm{s}$ \\
Initial temperature of preform & $700^{\circ} \mathrm{C}$ \\
\hline
\end{tabular}

metal. This value was verified using an infra-red thermometer and a K-type thermocouple.

\section{RESULTS AND DISCUSSIONS}

\section{Simulation Results}

The watch bezel used in this study was produced by reusing the scrap obtained during the watch case fabrication. The work flow for this process is illustrated in Fig. 7. The FE simulation software facilitated the relevant tooling design.

\section{Acquisition of Secondary Formed Components Through Warm Forming}

The simulation results of the warm-forming process, which produced the secondary formed components from two different hollow preforms (i.e., PA

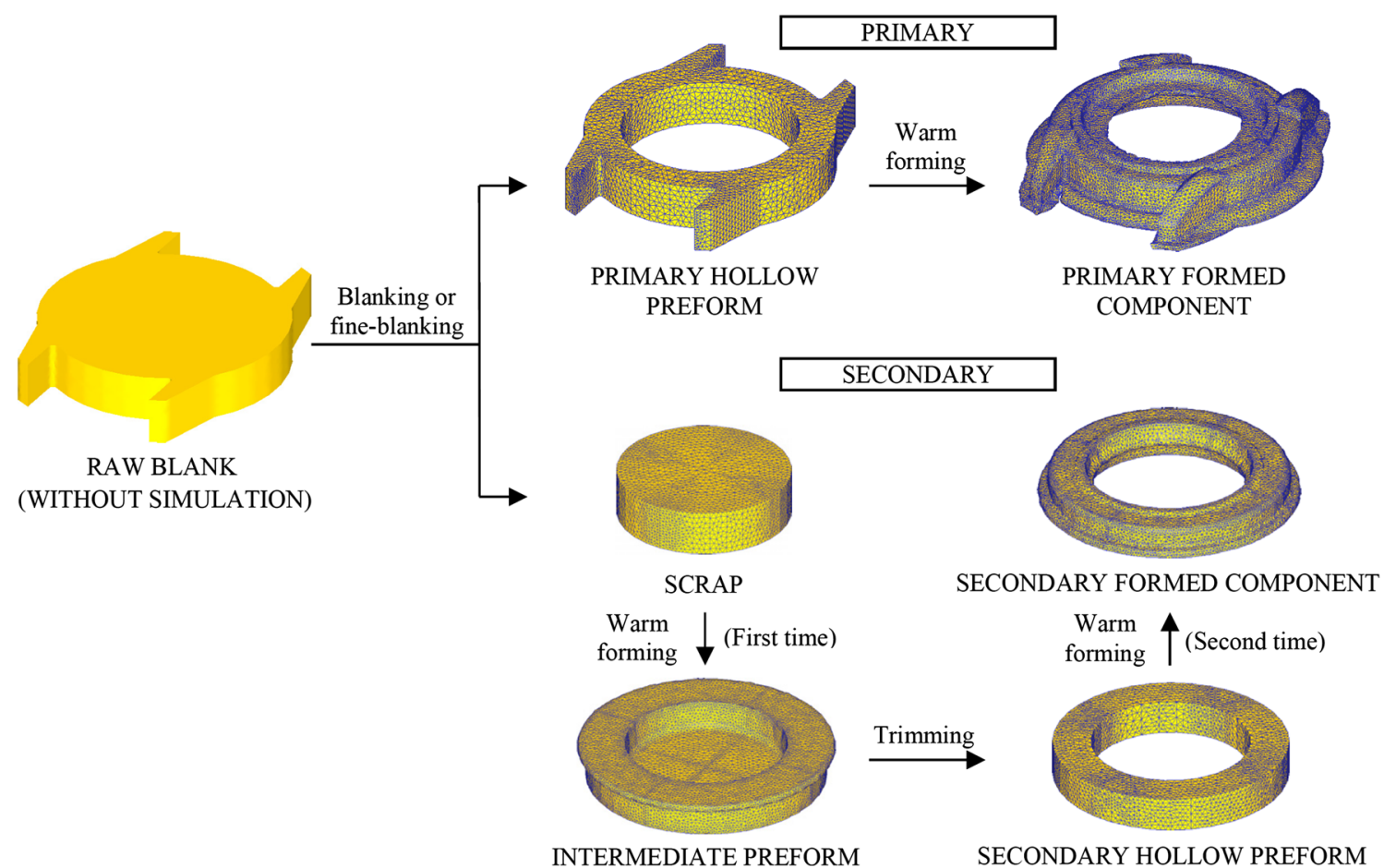

Fig. 7. The main flow illustrates overall production of primary and secondary formed components through simulation process.

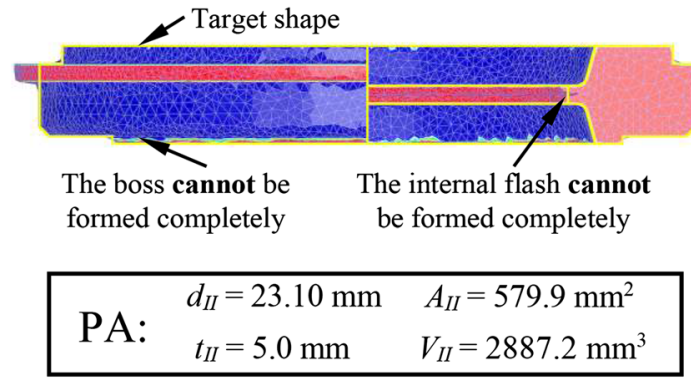

(a)

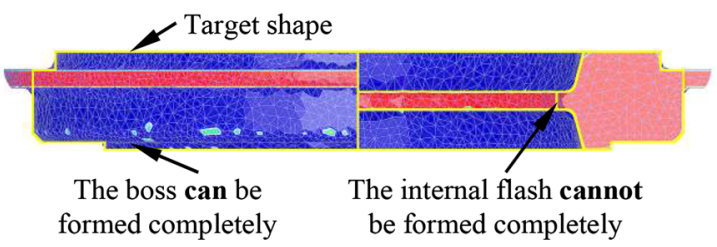

PB:

$$
\begin{array}{cc}
d_{I I}=24.10 \mathrm{~mm} & A_{I I}=539.2 \mathrm{~mm}^{2} \\
t_{I I}=5.4 \mathrm{~mm} & V_{I I}=2887.2 \mathrm{~mm}^{3}
\end{array}
$$

(b)

Fig. 8. The simulation results of warm forming for producing secondary formed components from (a) PA, and (b) PB. 
and $\mathrm{PB}$ ), are shown in Fig. 8. The main difference between the two was the die filling of the boss at top of the component (i.e., the die cavity bottom). The metal in the case of PB completely filled up the groove in the bottom die to form the entire boss. However, the metal in the case of PA only partially filled up that region. A shortcoming of internal flashes was also observed, which had no effect on the final product because these internal flashes were trimmed off after the forming process. Therefore, $\mathrm{PB}$ was the most appropriate design.

Schematic diagram of intermediate preform
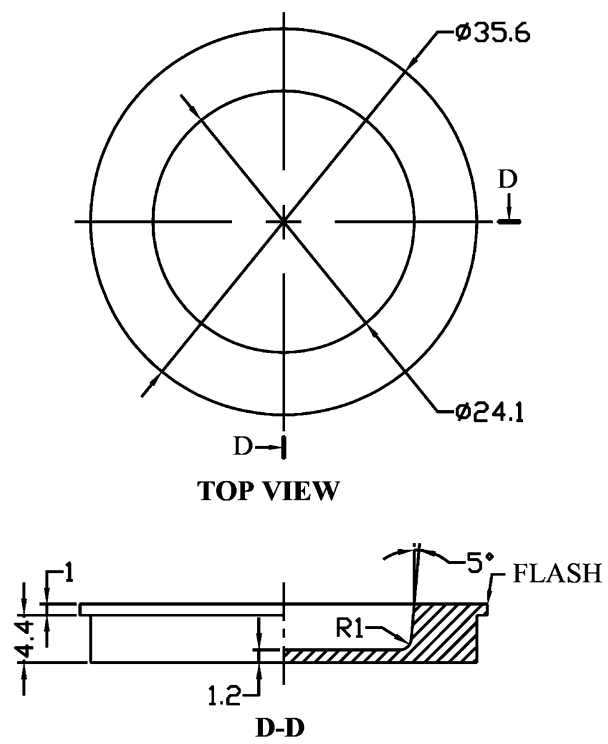

ALL DIMENSIONS IN MM

Fig. 9. The configuration of the intermediate preform.

\section{Warm-Forming Scraps for Intermediate Preform Production}

The PB design indicated that the $d_{\mathrm{II}}$ and $t_{\mathrm{II}}$ values were $24.1 \mathrm{~mm}$ and $5.4 \mathrm{~mm}$, respectively. The intermediate preforms illustrated in Fig. 9 were designed based on these two values. The total volume for the preform with $2.5 \%$ flash was $3617.8 \mathrm{~mm}^{3}$. A comparison of the data shown in Table V showed that only the scraps of P2 and P4 had sufficient volumes. Hence, P1 and P3 were rejected.

The simulation results of warm-forming the intermediate preforms from the scraps of P1, P2, P3, and $\mathrm{P} 4$ are shown in Fig. 10. Many regions of the die cavities in the scraps of $\mathrm{P} 1$ and P3 were not filled up because of the insufficient metal volume. By contrast, the metal completely filled up the die cavities in the scraps of P2 and P4. The amount of flash in P4 was higher because its scrap was larger in size. The flashes and excess materials at the bottom of the intermediate preforms were trimmed off to produce the secondary hollow preforms. Moreover, the scraps of P2 and P4 were used to fabricate the secondary formed component.

\section{Prediction of Primary Hollow Preform Design Using Reverse Method}

The simulation results of warm forming from five different hollow preforms (i.e., P1, P2, P3, P4, and P5) are presented in Fig. 11. Accordingly, the forming was successful under all five conditions. The die cavity was completely filled up. Furthermore, the excess material overflowed as flash toward the parting line. The flash formations for P2, $\mathrm{P} 3$, and $\mathrm{P} 4$ were similar even though their $d_{\mathrm{I}}$ and $t$ values were different. In addition, the amounts of internal and external flashes were nearly the same. The tapered punch extruded the central material of these three hollow preforms outward and subse-

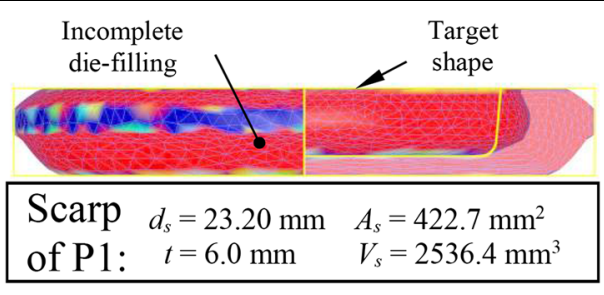

(a)

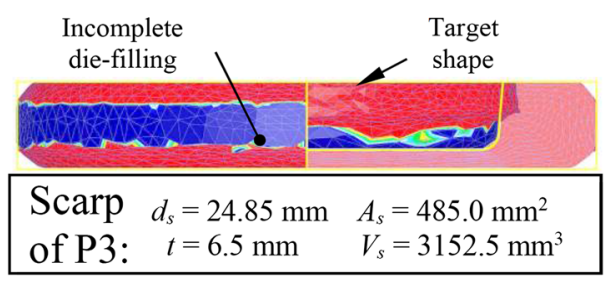

(c)

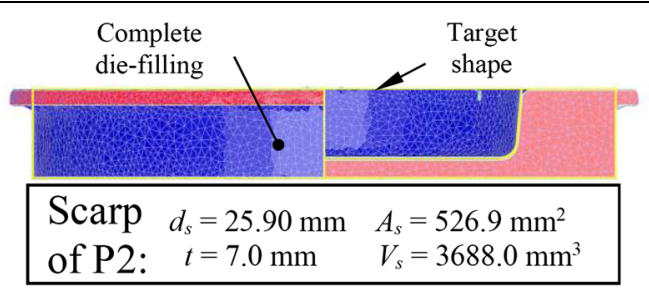

(b)

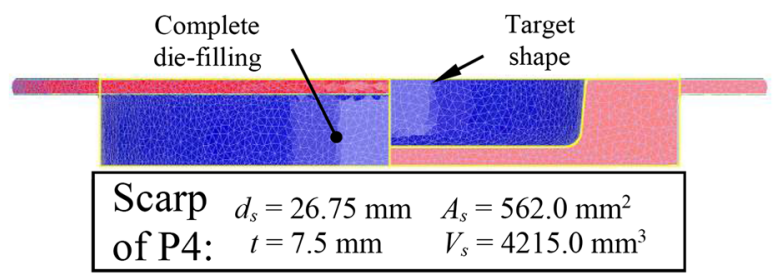

(d)

Fig. 10. The simulation results of warm forming for producing intermediate preforms from scraps of (a) P1, (b) P2, (c) P3, and (d) P4. 


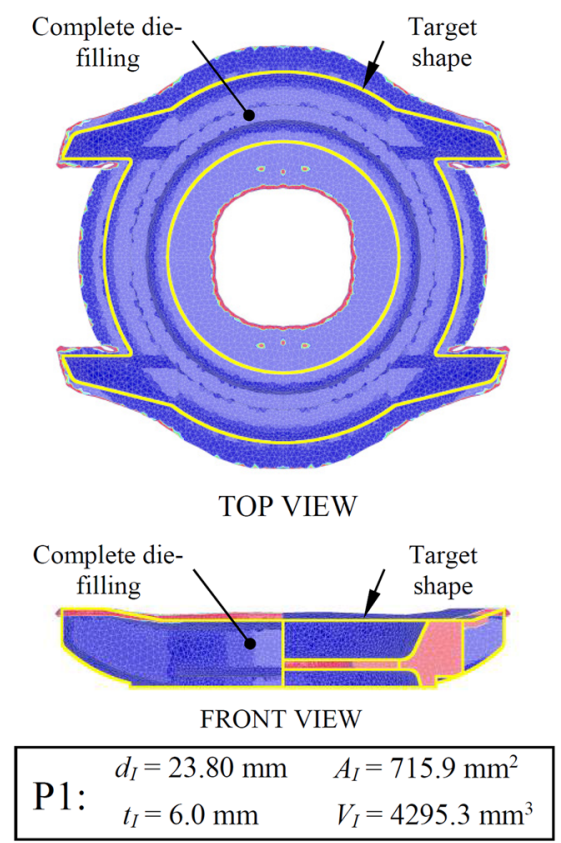

(a)
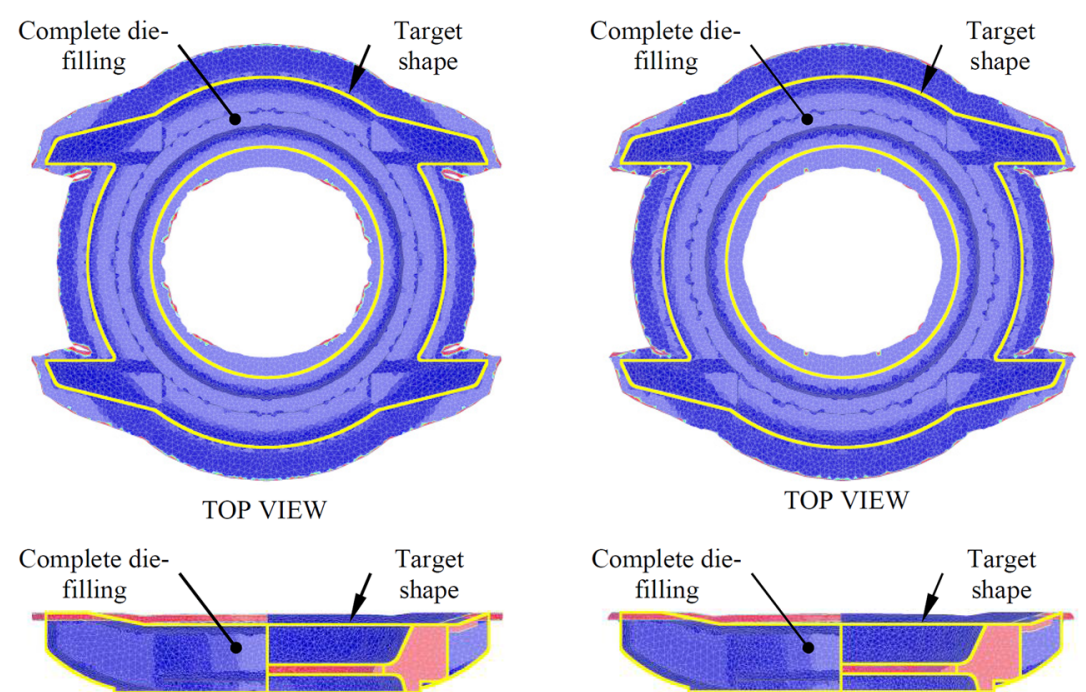

FRONT VIEW

P2: \begin{tabular}{cc|}
$d_{I}=26.60 \mathrm{~mm}$ & $A_{I}=605.1 \mathrm{~mm}^{2}$ \\
$t_{I}=7.0 \mathrm{~mm}$ & $V_{I}=4235.3 \mathrm{~mm}^{3}$
\end{tabular}

(b)

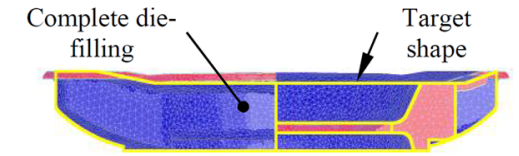

FRONT VIEW

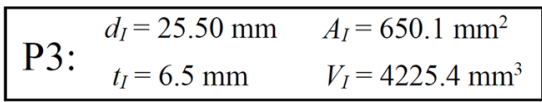

(c)

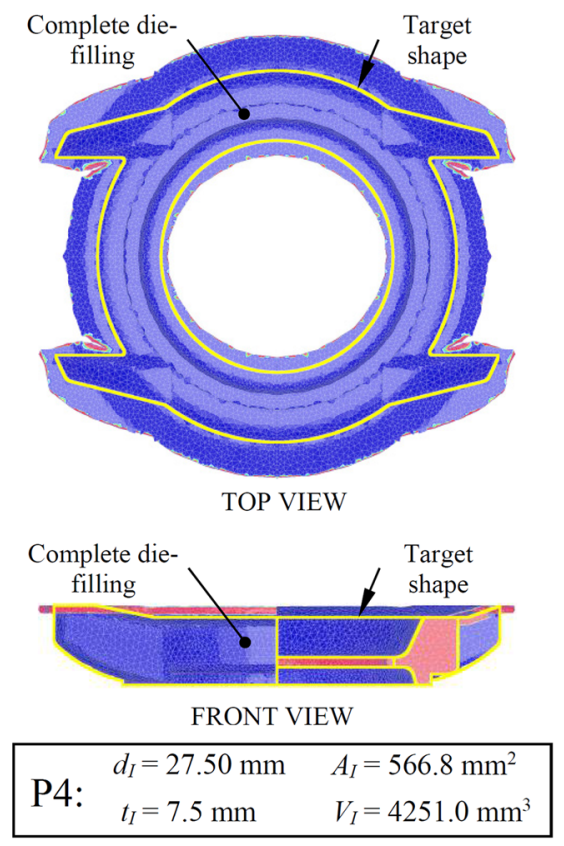

(d)
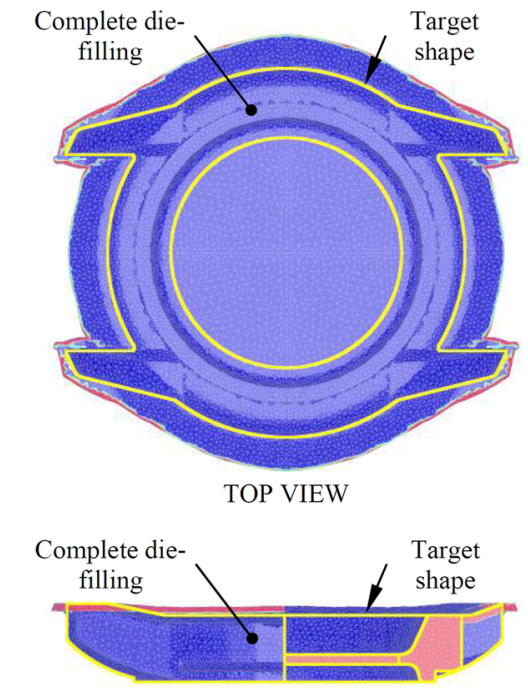

FRONT VIEW

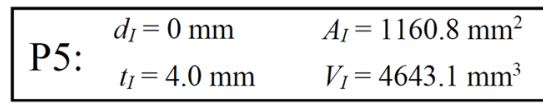

(e)

Fig. 11. The simulation results of warm forming for producing primary formed components from (a) P1, (b) P2, (c) P3, (d) P4, and (e) P5.

quently compressed them. An excessive amount of internal flashes was observed in P1. The $d_{\mathrm{I}}$ of $\mathrm{P} 1$ was set to $d_{1 \mathrm{p}}$ (i.e., $23.80 \mathrm{~mm}$ ), which was much smaller than $d_{2 \mathrm{p}}$ (i.e., $26.60 \mathrm{~mm}$ ), $d_{1 \mathrm{e}}$ (i.e., $25.50 \mathrm{~mm}$ ), and $d_{2 \mathrm{e}}$ (i.e., $27.50 \mathrm{~mm}$ ) for P2, P3 and $\mathrm{P} 4$, respectively. A larger amount of the central material in P1 was extruded, which caused the excessive amount of flashes along the center hole contours of the formed component.
P2 and P4 fulfilled the objective of this study because the scraps produced in forming the primary formed component of these designs were used to produce the secondary formed component. P2 was the most appropriate design because of its smaller $t$ and material cost (i.e., 7\%) lower than that of $\mathrm{P} 4$.

However, the best choice was P1 if the feasibility of using the scrap to form the secondary hollow 
preform was not considered. P1 was suitable because its $t$ value was the smallest among the primary hollow preforms. Although $t$ of the metal block for P5 was thinner than that of $\mathrm{P} 1$, the required forming load of P5 was much higher. The loadstroke curves in Fig. 12 demonstrate that the load is more than double the corresponding loads for the

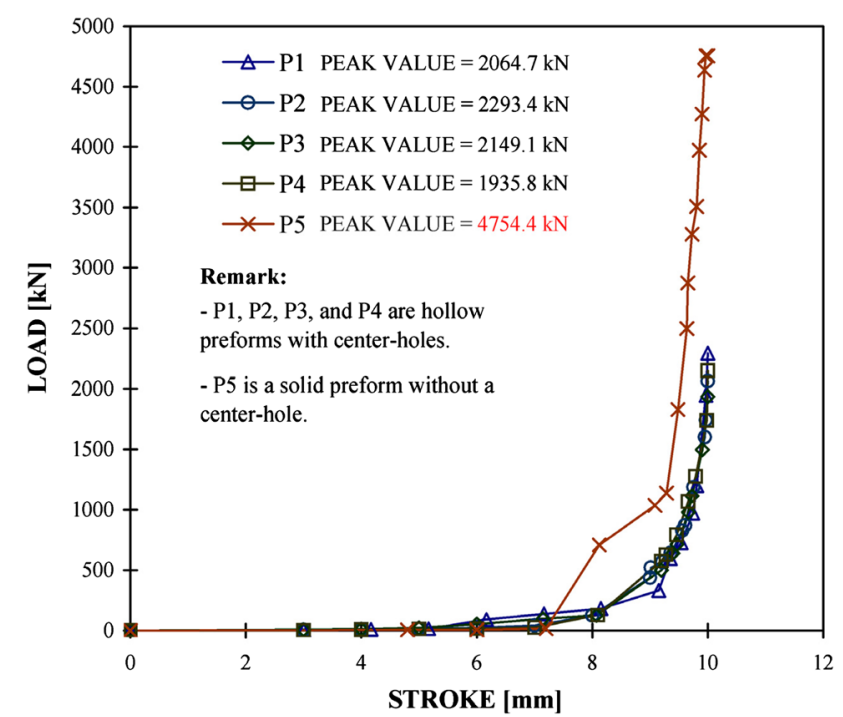

Fig. 12. The load-stroke curves of warm forming the primary formed components from P1, P2, P3, P4, and P5. hollow preforms. Forming the hollow metallic components using the hollow preforms was more economical because die life increased with decreasing loads.

\section{Verification by Experiments}

An experiment using custom-made tooling and a mechanical press specially modified for warm forming was carried out to compare and verify the results obtained from the simulation software. The AISI 316L stainless steel specimens were produced with the approximate dimensions of the best solution (i.e., P2 and its scrap). The $t$ values of the specimens were around $7.2 \mathrm{~mm}$ to $7.5 \mathrm{~mm}$ because of the die roll effect of blanking. $d_{\mathrm{I}}$ and $d_{\mathrm{s}}$, which were $26.6 \mathrm{~mm}$ and $25.9 \mathrm{~mm}$, were similar to the parameters used in the simulation. The specimens were processed following the procedures in Fig. 13. Accordingly, the process conditions of warm forming were compatible with the simulations.

No forming defect was nearly observed on the formed components. Moreover, the accuracy of their critical dimensions (e.g., total lengths, widths, heights, and flash thicknesses) was within $\pm 0.1 \mathrm{~mm}$. The components appearances were very similar to those predicted by the simulation software. The only discrepancy found was in the formation of an external flash near the lugs of the watch case. The formation was due to the die-roll

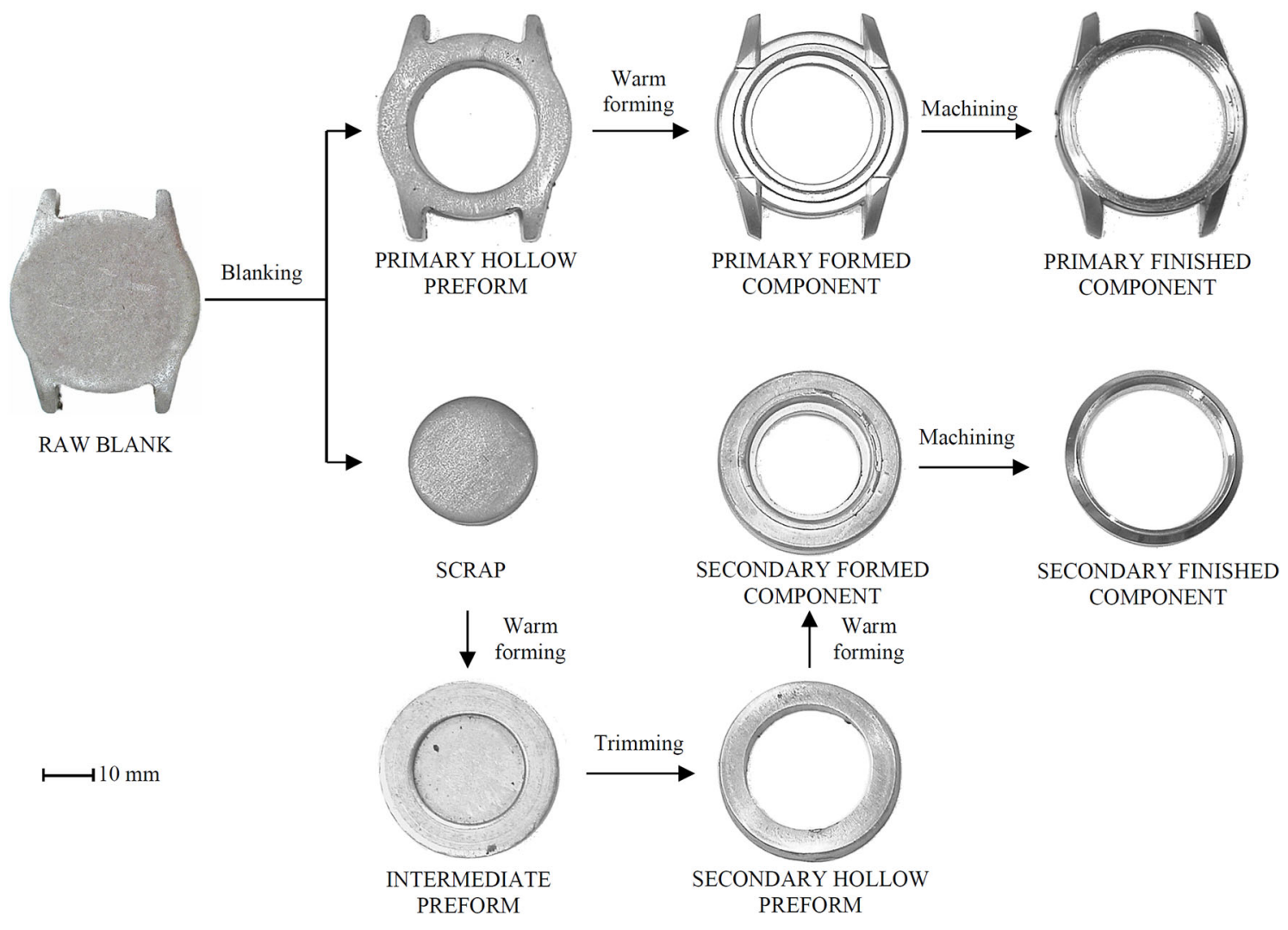

Fig. 13. The verification by physical experiments. 
Table VI. The comparison between conventional and proposed approaches

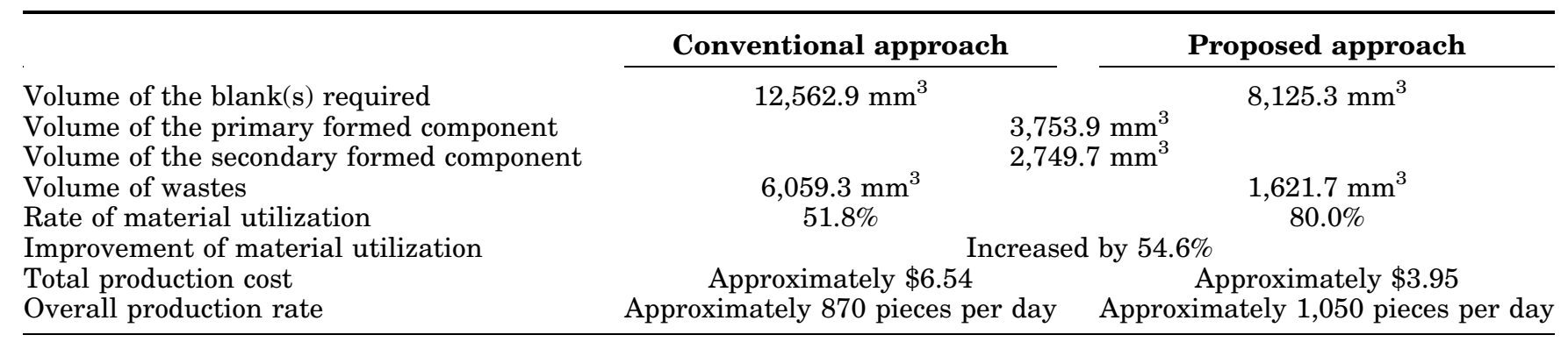

effect, which resulted in an uneven $t$ along the specimen edge. This error was acceptable because of the sufficient design margin between the formed components and the final machined product.

The metal might not be able to fill up some intricate regions of the die, especially at the outer region of the formed component where the simulation showed only a small amount of flash, if the total die roll of the raw blank was greater than $0.5 \mathrm{~mm}$. This error could cause a great discrepancy between the simulation and the actual experiment.

Approximately $40 \%$ of the total production cost was saved using the methodology reported in this article. In addition, the overall production rate increased by around 20\%. By contrast, the conventional method required two separate raw blanks with volumes of $6964.6 \mathrm{~mm}^{3}$ and $5598.3 \mathrm{~mm}^{3}$ for the watch case and bezel, respectively. These values led to a total volume of $12562.9 \mathrm{~mm}^{3}$, which was much higher than the $8125.3 \mathrm{~mm}^{3}$ volume presented in this study. The comparison of the conventional and the proposed approaches is presented in Table VI. The greatest benefit achieved was the $50 \%$ improvement in material utilization.

\section{CONCLUSION}

An analytical approach in designing primary and secondary hollow preforms for warm-forming intricate components was successfully developed using computer simulation. The AISI 316L stainless steel watch case and its bezel were fabricated and used as examples. The scrap of the primary hollow preform center hole was reused through careful design to produce the secondary hollow preform. The reuse resulted in more than 50\% improvement in the material utilization rate. The center-hole diameters (i.e., $d_{\mathrm{I}}$ and $d_{\mathrm{II}}$ ) and material thickness (i.e., $t_{\mathrm{I}}$ and $t_{\mathrm{II}}$ ) were significant geometric variables influencing the metal flow, die filling, and flash formation during the warm-forming process. Their values were successfully determined with the aid of computer simulation.

The proposed methodology was intensively verified through experimental work. The appearances of the formed components were very similar to those predicted by numerical simulations. This approach was satisfactory and able to improve greatly the efficiency of the warm-forming process design.

\section{ACKNOWLEDGEMENTS}

The work described in this article was supported by grants from the Research Grant Council of the Hong Kong Special Administrative Region, P.R. China (Project No. PolyU 511511).

\section{REFERENCES}

1. H.A. Kuhn and L.B. Ferguson, JOM 36, 69 (1984).

2. A.G.K. Jinka, JOM 47, 42 (1995).

3. B.P.P.A. Gouveia, J.M.C. Rodrigues, and P.A.F. Martins, J. Mater. Process. Technol. 73, 281 (1998).

4. H.C. Altmann and W.J. Slagter (Paper presented at NUMIFORM-Proc. of 7th International Conference on Numerical Methods in Industrial Forming Processes, Toyohashi, Japan, 2001).

5. S.I. Oh, W.T. Wu, and K. Arimoto, J. Mater. Process. Technol. 111, 2 (2001).

6. G. Li, J.T. Jinn, W.T. Wu, and S.I. Oh, J. Mater. Process. Tech. 113, 40 (2001).

7. M.L. Alves, J.M.C. Rodrigues, and P.A.F. Martins, Model. Simul. Mater. Sci. 11, 803 (2003).

8. G.E. Dieter, H.A. Kuhn, and S.L. Semiatin, eds., Handbook of Workability and Process Design (ASM International: Materials Park, OH, 2003).

9. T.J. Shin, Y.H. Lee, J.T. Yeom, S.H. Chung, S.S. Hong, I.O. Shim, N.K. Park, C.S. Lee, and S.M. Hwang, Comput. Method Appl. M. 194, 3828 (2005).

10. L.H. Lang, A.J. Xu, and F. Li, JOM 64, 309 (2012).

11. J.J. Park, N. Rebelo, and S. Kobayashi, Int. J. Mach. Tool. D. R. 23, 71 (1983).

12. S.I. Oh and S.M. Yoon, CIRP Ann. Manuf. Technol. 43, 245 (1994).

13. S.K. Biswas and W.A. Knight, Int. J. Mach. Tool. D. R. 15, 179 (1975).

14. S. Sheng and L.Y. Guo, J. Mater. Process. Technol. 34, 349 (1992).

15. C.S. Han, R.V. Grandhi, and R. Srinivasan, AIAA J. 31, 774 (1993).

16. R.Y. Lapovok and P.F. Thomson, Int. J. Mach. Tool. Manuf. 35, 1537 (1995).

17. H.Y. Kim and D.W. Kim, J. Mater. Process. Technol. 41, 83 (1994).

18. T. Takemasu, V. Vazquez, B. Painter, and T. Altan, J. Mater. Process. Technol. 59, 95 (1996).

19. V. Vazquez and T. Altan, J. Mater. Process. Technol. 98, 81 (2000).

20. S.M. Hwang and S. Kobayashi, Int. J. Mach. Tool. D. R. 26, 231 (1986)

21. G. Zhao, E. Wright, and R.V. Grandhi, Int. J. Mach. Tool. Manuf. 35, 1225 (1995).

22. G. Zhao, Z. Zhao, T. Wang, and R.V. Grandhi, J. Mater. Process. Technol. 84, 193 (1998).

23. K. Lange and H. Meyer-Nolkemper, Close-Die Forming (in German) (Berlin: Springer, 1977).

24. S. Fujikawa, H. Yoshioka, and S. Shimanmura, J. Mater. Process. Technol. 35, 317 (1992). 
25. M. Hirschvogel and H.V. Dommelen, J. Mater. Process. Technol. 35, 343 (1992).

26. G.E. Totten, K. Funatani, and L. Xie, eds., Handbook of Metallurgical Process Design (New York: Marcel Dekker, 2004).

27. Y.V.R.K. Prasad and S. Sasidhara, Hot Working Guide: A Compendium of Processing Maps (Materials Park, OH: ASM International, 1997).
28. Allegheny Ludlum Steel Corporation, Stainless Steel Fabrication (Pittsburgh: Allegheny Ludlum Steel Corporation, 1957). https://books.google.com.hk/books?id=TOJTAAAAMA AJ\&q=\%22Stainless+Steel+Fabrication $\% 22+1959 \& d q=\% 22$ Stainless+Steel+Fabrication\%22+1959\&hl=zh-TW\&sa=X\& ei=0oqOVNHpK-OxmAXIsICIBg\&ved=0CB0Q6AEwAA

29. Schuler GmbH, Metal Forming Handbook (New York: Springer, 1998). 